\title{
The Effect of Type of Training in Operational and Servicing Tasks on Changes in Self-Efficacy
}

\author{
TENNAKOON, W.D.N.S.M. \\ Department of Business Management, \\ Faculty of Business Studies \& Finance, \\ Wayamba University of Sri Lanka, \\ Kuliyapitiya \\ SRI LANKA \\ tennakoon@wyb.ac.lk
}

\begin{abstract}
:-
Employee Training and Development (T\&D) should address not only their knowledge \& skills but attitude \& self-perception as well. The effects of T\&Ds are not identical. The study investigates the varying effects of different trainings for operational and servicing tasks. The findings would aid to motivate employees and to design effective T\&Ds. The study utilized an experimental design. The data was analyzed using two factor analysis of variance technique. The effect of different types of trainings on self-efficacy (SE) found to be vary from one task to another. The mastery experience remains as the most effective training for both tasks. The effects of vicarious experience and verbal persuasion are less predictive. Employee T\&Ds are needed to base on the evaluation of relative effect of SE antecedents for a specific task. This will improve the effectiveness of T\&Ds while keeping the cost of them lowest as possible.
\end{abstract}

Key Words: Employee Training and Development (T\&D), Self-Efficacy (SE) 


\section{Introduction}

Human resource is an integral part of any organization. Great stress is laid on effective utilization of available human resources within an organization. Human performance is a factor when contemplating how to increase organizational performance in most, if not all organizations. The factors such as significant developments in technology and research, demographic and sociopolitical shifts, and the trend towards globalization have accelerated the pace of environmental changes. Organizations must be able to adapt to the rapidly changing environment in order to preserve their survival.

Once the importance of human performance is identified as a significant factor towards the organizational performance, the challenge becomes improving human performances. The requisite skill (or knowledge) and SE are the two resources, a person needs to successfully perform any task (Bandura, 1982, 1997; Wood \& Bandura, 1989). In many cases, a certain level of skill or knowledge is a requirement of employment. The knowledge acquisition and enhancement is routinely addressed in many organizations, e.g., employee training and development, tuition assistance, on the job training, apprenticeships, etc.

Employee Training and Development (T \& D) is an important human resource development function of any organization. Organizations spend huge sum of money to train their employees. $\mathrm{T} \&$ Ds are mainly aimed at improving employee performance through upgrading employees' SE. They make employees ready to accept current and future job requirements. They offer the knowledge, skills and abilities to perform a certain task. Although many possess the requisite level of knowledge or skill to perform a given task, few perform at an optimum level. It is posited that this is reflective mostly of a variance in SE. SE is the one's own assessment of his/her capability to perform any activity (Bandura, 1977) SE affects the level of motivation to perform any task. They are task-specific and changes over time.

Once the importance of employees' SE towards organizational performance is identified, managers would ideally look in to the venues through which they can influence employees' SE. But this cognitive process is unmanageable which is beyond the control of humans. Yet the managers can exercise their 
control over the SE through employee T \& D.

For instance, if employees are given chances for "try outs" before assigning an important task, that leads to improve employee's SE through mastery experiences. Moreover frequent appraisals by manager and peers regarding one's ability to do something is a sound form of verbal persuasion that leads to develop SE. In that ways SE antecedents can be treated as more powerful motivational force which is more sustainable than the other general form of monetary and non-monetary incentives. As the organizational performance relies on the employees' performances, the concept of SE should be given greater attention by people who are managing human resources towards organizational succession.

Given the existence of different types of tasks, it can be reasonably questioned that the effectiveness of different types of trainings hold identical over the wide range of tasks. Any job should be design in a way that facilitate employee to gather more training in his/her job context. The employee supervision should also be done in a way that provides them relevant training. For that managers should well aware about the effectiveness of different types of trainings for different task types. The knowledge about the effectiveness of different types of trainings for each task category is utmost important. That will help to cut down the T \& D cost and to use T \& D funds effectively.

T \& Ds upgrades the SE of employees (Luthans, 1980). Although SE could be the foremost method of increasing the performance of an organization's members, little research has been done to investigate methods of influencing SE in organizational settings.

Accordingly, this research investigates the effectiveness of different types of trainings to form SE beliefs for different types of tasks.

The findings of the study would aid in streamlining the human resource function of organizations by means of providing the fundamental knowledge about the effectiveness of different types of trainings for certain task categories.

\section{Literature Survey}

Bandura (1978, p.240) defined SE as "a judgment of one's ability to execute a particular behavior pattern". It plays a central role in self-regulatory process to affect the motivation and performance attainments (Wood \& Bandura, 1989). 
SE judgments also determine how much effort people will spend on a task and how long they will persist with it. People with strong SE beliefs exert greater efforts to master a challenge while those with weak SE beliefs are likely to reduce their efforts or even quit (Bandura \& Schunk, 1981).

$\mathrm{SE}$ is dynamic. It changes over time with new information and experience (Gardner \& Pierce, 1998; Gist \& Mitchell, 1992). SE applies to wide range of situations and is a good predictor of subsequent performance and behavior (Bandura, 1978, Gist \& Mitchell, 1992). Cole and Hopkins (1995) reported a strong, significant correlation between individual SE and performance. Several other researchers have supported the notion that SE is a correlate of performance (Bandura, 1991; Gibson, 2001; Malone, 2001). Stajkovic and Luthans (1998) in metaanalysis report that SE explains a $28 \%$ increase in performance as compared to organizational behavior modification (17\%), feedback interventions (13.6\%), and goal setting (10.9\%). Additionally, $\mathrm{SE}$ is thought to play a critical role in influencing effectiveness, perceived productivity, job satisfaction, and ability to cope in remote workers (Staples, Hulland \& Higgins, 1999).

\section{Self-efficacy Antecedents}

People's beliefs about their efficacy can be instilled and strengthened in four principle ways; mastery experiences, modeling (vicarious experience), social persuasion, and judgments of their physiological states (Bandura, 1977, 1997; Wood \& Bandura, 1989). Hence these are treated as antecedents of SE. In order of strength, the first is performance accomplishments/mastery experience. It refers to personal assessment of information that is based on an individual's personal mastery accomplishments (i.e. past experiences with the specific task being investigated). Previous successes raise mastery expectations, while repeated failures lower them (Gist \& Mitchell, 1992; Saks, 1995; Silver, Mitchell \& Gist, 1995).

The second is vicarious experience, which is gained by observing others perform activities successfully. This is often referred to as modeling, and it can generate expectations in observers that they can improve their own performance by learning from what they have observed (Bandura, 1978; Gist \& Mitchell, 1992).

Social persuasion/verbal persuasion is the third antecedent. It refers to activities where people are led, through 
suggestion, into believing that they can cope successfully with specific tasks. Coaching and giving evaluative feedback on performance are common types of social persuasion (Bandura, 1977; Bandura \& Cervone, 1986).

The final source of information is physiological and emotional states. The individual's physiological or emotional states influence SE judgments with respect to specific tasks. Emotional reactions to such tasks (e.g. anxiety) can lead to negative judgments of one's ability to complete the tasks (Bandura, 1988).

The first three SE antecedents on the other hand resemble the forms of $\mathrm{T} \&$ Ds offer to employees aiming better performances. Here in this study, these SE antecedents are here in after referred as types of trainings. The effect of each type of training on changes to SE is not identical (Bandura, 1977, 1997; Wood \& Bandura, 1989). The effectiveness of them depend on the task been addressed.

\section{Types of Tasks}

Formation of SE beliefs highly varies across different task domains. This is caused by varying power of each SE antecedent depending on the nature of the tasks. The commands of each SE antecedent gets strengthen or weaken depending on the task. For instance a bank assistant may highly efficacious in balancing the daily transactions while s/he may not be that much efficacious for processing a loan. Greater will be the differences among the tasks the greater the variation in SE belief.

A task is defined as an activity; the task doer performs in order to accomplish a goal (Vakkari, 2003). A task is considered as an important factor influencing human being's behavior in social psychology and organizational management. Yuelin Li (2004) introduced a faceted classification of task under which tasks are classified based on sources of tasks, task doer, time, product; results of task completion, action; how a task is completed, goal, task characteristics; task attributes related to a task itself, and users' perception of task; task attributes related to users' perception. Task characteristics base and task attributes base classify task into two namely; physical and intellectual tasks. Physical tasks are characterized by generating a value by producing physical products. An intellectual task produces new ideas or findings, and decision/solution for a problem. 
Kotller (2000) came out with a classification of task based on their attributes. He identified five categories of offerings/ service mix; pure tangible offerings, tangible offering with accompanying services, hybrid, major service with accompanying minor offerings and services, and pure services. When distinguishing services from products, Kotller (2000) works on four characteristics which are equally applicable of distinguishing servicing tasks from operational tasks as well. They are intangibility, inseparability, variability, and perishability. Unlike physical products /operations, services cannot be seen, tasted, felt, herd, or smelled. The production and consumption of services occur simultaneously and this is not true for physical products/operations. Because the client is also present as the service is produced, service provider - client interaction is a special feature of services marketing. Services depend on who provides them and when and where they are provided, they are highly variable. Dissimilar to products or manual operations services cannot be stored.

The study utilized the product based classification of tasks which classify tasks into two namely; physical task and intellectual task. This notion is supported by Kotller's above classification of offerings too. The terms "operational tasks" and "servicing tasks" have been operationally defined for the study purpose while they denote physical tasks and intellectual tasks respectively. The researcher paid her special attention on the nature of the skills needed to perform each task while adopting above classification. Accordingly the operational tasks demands more technical skills while servicing tasks need more conceptual and analytical skills.

The production of services are communal activities by an employee and a second party i.e. customer. Social perception about the capacity of that particular employee to perform that task put a great weight on the effective functioning of the employee. For instance if an Insurance Executive is been told by one of his client, that "I am having doubts whether you can get your company to pay back the premium payment I made for getting extra facilities which were lately given to all customers free of charge", it may negatively influence the SE of that Insurance Executive regardless of having several success stories by him (mastery experience) and having heard of his friends were succeed in similar situations (vicarious experience). 
Thereby the effect of trainings on SE varies for different tasks.

This study is primarily based on Bandura's $(1977,1997)$ work on SE that posited there are four different sources of SE. The effectiveness of them varies depending on the nature of the given task (Bandura, 1977). The effects of three types of trainings on SE for operational tasks \& servicing tasks were assessed and analyzed.

The conceptual association among the variables is exhibited by the figure 1 .

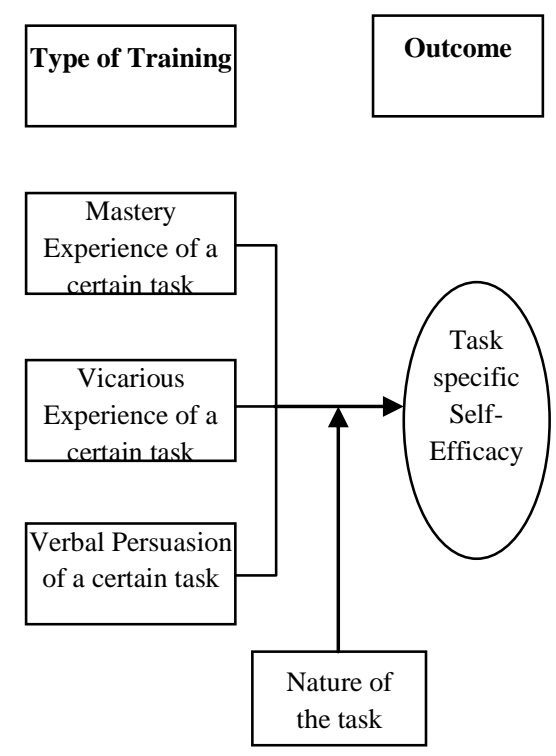

\section{Figure 1}

\section{The Conceptual Framework}

Note: Top-down order of the different types of trainings represents their relative effectiveness to determine the SE beliefs of employees for a given task.

Given the conceptual association of type of trainings and SE beliefs across diverse task domains with performance, and their possible associations with each other, it is important to investigate their joint influence on work-related performance.

Yet, surprisingly little research has investigated these joint influences. Accordingly this study investigated the effectiveness of different types of trainings to form SE beliefs for operational tasks and servicing tasks.

\section{Methodology}

The research design was a mixed experimental design $(2 \times 2 \times 3)$. The independent variable was the type of training. There were three types of trainings. They are equivalent to three main SE antecedents namely; mastery experience, vicarious experience, and verbal persuasion. The dependent variable was the task specific SE.

The type of task was treated as the moderating variable. It moderates the relationship between type of training 
and SE beliefs. This was operationally defined as operational task and servicing task for the purpose of the research. The operational task was running a Decision Support System (DSS) i.e. a computer software application that aid in making less structured managerial decisions. The servicing task was giving a negative Performance Feedback to a subordinate (NPF).

The questionnaires were used to collect data. The instrument incorporated a 3point scale to measure the type of training, a 2-point scale to rate the type of task, and a 10-point scale to measure the task specific SE which is the standard methodology for measuring efficacy beliefs (Bandura, 2001). The reliability of the scales and the internal consistency of measurements are tested using cronbach's alpha technique which reported 0.955 , and 0.983 , for SE scale and scale for the type of training respectively. An analysis of interdependence (i.e. principal component factor analysis) has been utilized to ensure the homogeneity of the scales as recommended by Bandura (2001). This ensures the scales are high in their construct validity as the $1^{\text {st }}$ component accounts for 92.642, and 92.373 variance for SE scale, and scale for type of training, respectively.

\section{The Participants}

Ninety (90) Management trainees were chosen as the participants of the experiment. They are undergoing learning and apprenticeship simultaneously. They have low mastery of routine managerial activities compared to experienced managers. It controls the effect of higher mastery experience on the manager's SE.

The research was designed to explore the empirical evidences for a prevailing theoretical concept. Therefore, a fairly representative sample was scanned whereas it is unlikely in case of generalization of a concept.

The researcher had paid her attention to preserve the homogeneity of variables than trying to maintain generalizability. The homogeneity of participants was entrusted by choosing management trainees from a single academic year. They represent the same faculty of a selected university. A particular batch of management trainees composes of individuals with fairly similar backgrounds in education, skills \& competencies, and demographic characteristics. That aided to control the influence of variables such as education background, experience, and age ...etc. The homogeneity among variables was further ensured by selecting two specific 
tasks. Moreover, the participants were assigned to groups based on random assignment.

\section{The Data Collection Procedure}

Six groups were formed to represent 3 types of trainings under two types of tasks (3 types of trainings $\mathrm{x} 2$ types of tasks). The respondents were tested before and after the trainings. The trainings were based on two specific task categories. The operational task was to make a decision using a DSS. A trail version of a DSS developed by Vanguard Software Corporation namely; "DecisionPro" was used for the experiment. The servicing task was to communicate a negative performance feedback to a subordinate. A training material of New Market Learning Company was used here. The video named as "How to give a negative performance feedback at workplace”.

Three groups were given with the training about the DSS. A demonstration of the DSS was shown to participants of the group 1. Then they were asked to make a decision using the DSS by their own. The group 2 was provided with the same demonstration. Subsequently they were given the opportunity to watch how a peer of them is using DSS to make a decision. The group 3 was persuaded verbally to run the DSS after demonstrating the functionality of DSS.

In the same way, other three groups were provided with the training to give a negative performance feedback to a subordinate. The video was shown to the group 4. Each participant was then asked to convey a given negative performance feedback to another participant. They were reassessed once every participant got the opportunity to communicate a negative performance feedback by his/her own. The participants of group 5 too watched the video. Additionally, they observed how couple of participants is engaged in performance interview where a negative performance feedback is communicated. The group 6 was given only the chance to watch the video but was encouraged verbally to perform that task.

\section{Analysis}

The variances in SE among and within the groups were tested using Two factor analysis of variance technique (repeated measure). The experiment (mixed design - $2 \times 2 \times 3$ ) satisfied all the requirements for an analysis of variance technique (i.e. sample size $>30$, normal distribution, random assignments, etc...). A test for normality is conducted as the said model assumed normally distributed data. The data set is 
normally distributed. The Shapiro-Wilk test for normality recorded $0.147, .0 .376$, $.050, .069,0.063$, and 0.262 for data sets of six groups respectively. The researcher adopted 95\% significance level as the influence of other factors was properly manipulated during the experiment.

\section{Discussion of Findings}

The main objective of the study was to assess the effectiveness of different types of trainings to alter the employees' SE beliefs for different tasks. This is achieved by comparing the mean self - efficacies of different groups. Significant variances among the groups' mean SE evidenced the varying effect of different types of trainings for different tasks.

The conclusions were derived based on the results of two factor analysis of variance (repeated measure) technique.
The assumption of Sphericity is not violated. Thus, the hypothesis can be tested based on the results of the multivariate test (see Appendix Table $1)$.

\section{The Self-Efficacy and Trainings}

Theoretically trainings should uplift the SE as they represent the sources of SE. The time 2 SE demonstrates a significant variance from time $1 \mathrm{SE}$. Hence there are enough statistical evidences to conclude that the trainings affect to improve the generalized SE.

The comparison of pre-experimental and post experimental results also demonstrates that the training have caused improving the SE of respondents in all groups.

The table 2 summarizes the mean SE under each type of training at the two phrases of the experiment.

\section{Table 2}

The Pre-Experimental and Post-Experimental Mean Self-Efficacy

\begin{tabular}{lcc}
\hline \multicolumn{1}{c}{ Type of Training } & $\begin{array}{c}\text { Pre-Experimental Mean } \\
\text { SE (Time 1) }\end{array}$ & $\begin{array}{c}\text { Post-Experimental Mean } \\
\text { SE (Time 2) }\end{array}$ \\
\hline Mastery Experience & 3.5 & 5.667 \\
\hline Vicarious Experience & 3.067 & 4.2 \\
\hline Verbal Persuasion & 2.733 & 3.567 \\
\hline
\end{tabular}


Every type of trainings are seemed to be affect to improve the SE. By now it is clear that the training has an impact over the SE of management trainees. Let's examine whether the said impact is caused by the differences of trainings to ascertain the relative effect of each type of training.

\section{The Self-Efficacy and Type of Training}

A significant variance exists among the groups those represent three types of trainings (see Table 1). This variance is caused by the differences in trainings. That implies the effect of training on SE varies depending on the type of training. Moreover the pre-establish order of SE antecedents according to their relative power is maintained under both conditions where mastery experience scored greater mean SE, while vicarious experience and verbal persuasion recorded second and third places respectively (see table 2). Accordingly, the different types of trainings have varying effect over the task specific SE.

\section{The Self-Efficacy and Type of Task}

Now it is vital to investigate whether the different types of task have caused variances in SE among the groups. The mean SE of groups representing two tasks should vary significantly. The Based on the results it was found out that the SE beliefs vary depending on the task been addressed by the training (see Table 1).

The Effect of Different Types of Trainings on Self-Efficacy for Different Types of Tasks

Once the sole impact of type of training and type of task is discovered, it make necessary to test their combine effect on SE. The effect of trainings on SE varies depending on the type of task. To test the above interaction, the effect of different types of trainings on SE should be assessed in terms of different tasks. The results include sufficient statistical evidences to conclude that a significant interaction exits between types of trainings and types of tasks (see Table 1). This implies that the effect of trainings over SE varies depending on the task been performed.

The table 3 presents mean SE of groups based on different combination of trainings and tasks. 
Table 3

The Mean Self-Efficacy for Different Task Types along with Different Types of Trainings

\section{Type of Training}

Mean SE for giving a Negative Performance Feedback

\begin{aligned} & 1. Mastery \\ & Experience \\ & \hline 2. Vicarious \\ & Experience \\ & \hline 3. Verbal Persuasion \\ & \hline\end{aligned}

As per the table 3 , the order of $\mathrm{SE}$ antecedents is clearly maintained in case of operational task. But it is hard to pullout such pattern from the servicing task groups. The first two types of trainings seem more effective for forming SE beliefs for operational tasks than they work for servicing tasks. They record higher mean SE for both tasks. But this pattern works in other way for verbal persuasion. It demonstrates greater power to form SE beliefs for servicing task than for operational task (see table 3). That implies the effect of verbal persuasion is unpredictable and may vary depending on the type of task.

Hence the mastery experience is considered to be the most effective training, next vicarious experience and
5.4 3.8

3.43 .73

thirdly verbal persuasion for operational task (see table 3).

In contrast to that, the pre-established order of SE antecedents is hardly visible in servicing task data set. The mastery experience remains as the most effective training even for servicing task. Unlike the case of operational task, the effect of vicarious experience and verbal persuasion are indistinguishable. The two mean SE scores are relatively identical (see table 3). Both trainings are equally effective to form SE beliefs for servicing tasks. Thereby the preestablished order of SE antecedents is not maintained with respect to servicing tasks. This is can be further illustrated by the plot of estimated marginal means as shown by the figure 2 . 
Estimated Marginal Means of MEASURE_1

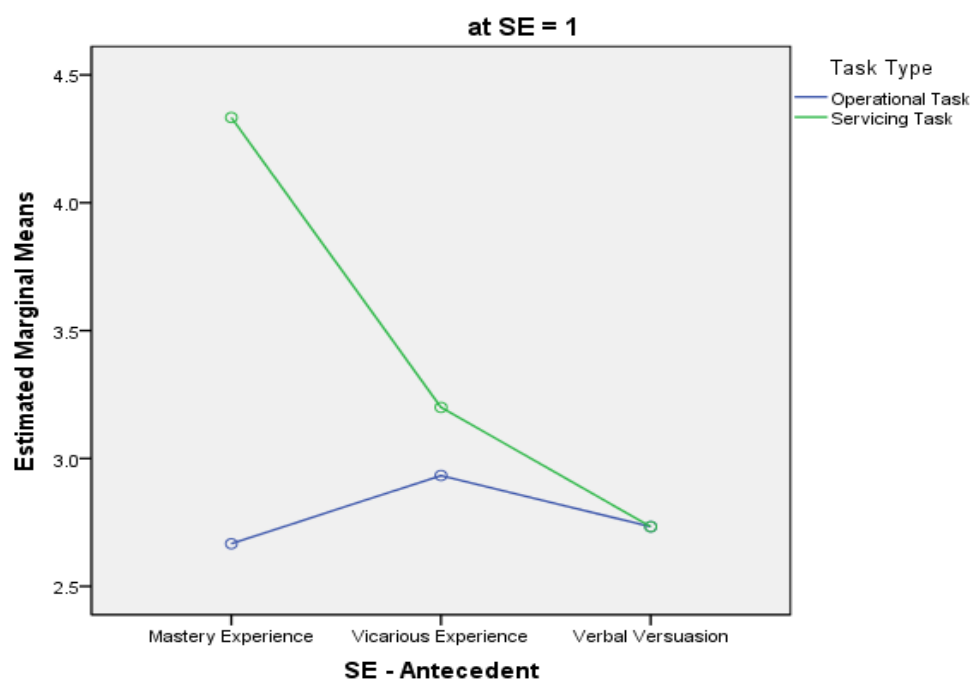

Estimated Marginal Means of MEASURE_1

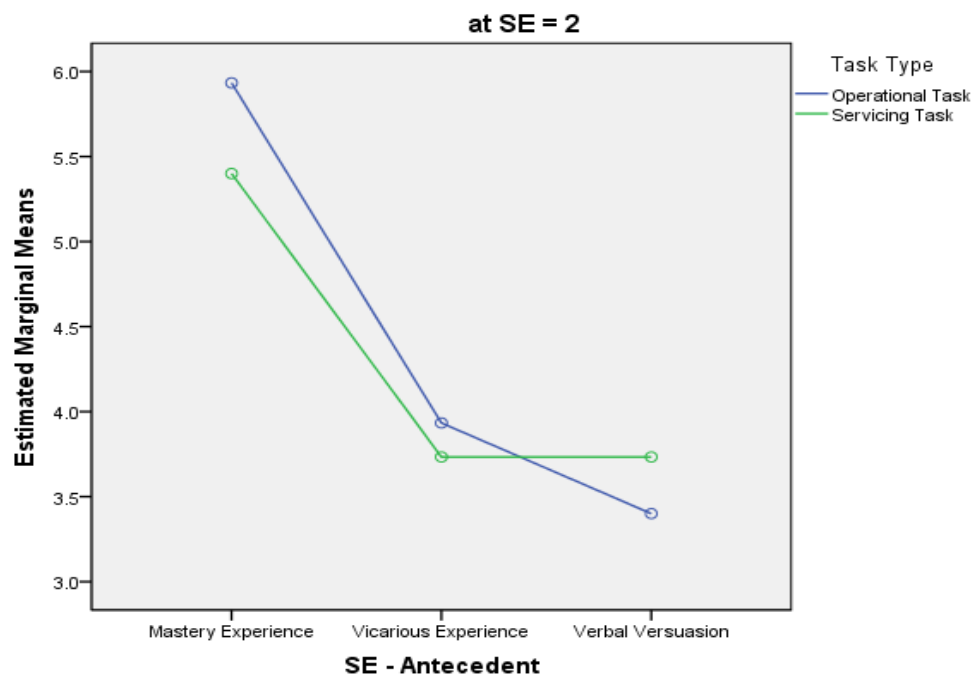

Figure 2

\section{Plot for Estimated Marginal Mean Self-Efficacies (Time 1 and Time 2)}

The differences in type of trainings have highest SE scores for operational task is caused varying SE scores in six groups. ranked by mastery experience, then As per the above plot, (see figure 2) the vicarious experience, and thirdly the 
verbal persuasion. Notably the said pattern is not maintained under servicing tasks where the vicarious experience and verbal persuasion seems to be equally effective to form SE belief for servicing tasks (see figure 2). The mean differences of vicarious experience \& verbal persuasion and verbal persuasion \& vicarious experience are recorded as insignificant.

Accordingly it is established that the effect of different types of trainings on SE vary depending on the task been performed.

\section{Conclusion}

The study succeeded in deriving significant implications for theory. First, this research empirically demonstrated that the trainings uplift the SE beliefs. Second, the effectiveness of three main SE antecedents to change the SE beliefs varies depending on the type of tasks. Mastery experience remains as the most effective type of training for operational and servicing tasks. But the relative effect of vicarious experience and verbal persuasion varies depending on the context. They heavily depend on the nature of the task.

As a prerequisite to influence the SE leaders are to be trained for a general awareness of SE and its effect on the people of an organization and consequently, the organization itself. The leadership of any organization where people are essential to the firm's success should take an active interest on this regard. The SE of employees should be assessed in relation to each significant task that is expected of them. Moreover, it should be routinely reassessed as SE changes over time with additional experiences. An attempt to influence SE can only be made when leadership is aware of its impact on performance and has an appraisal of each member's SE toward job requirements.

Once leaders become aware of the effect of SE and acquire efficacy appraisals, they must be trained to understand and influence the immediate antecedents of SE; i.e. mastery experience, vicarious experience, verbal persuasion, and physiological arousal. They can base the $\mathrm{T} \& \mathrm{D}$ programmes based on the most significant SE antecedent. In general, a leader must continuously strive to provide exposure to strong efficacy antecedents while limiting exposure to adverse efficacy antecedents. This becomes more challenging as the constraints that many leaders face in today's organizations, e.g. resource shortfalls, time constraints, a rapidly changing environment, etc... 
Given the direct correlation between trainings and $\mathrm{SE}$ and sequentially, between $\mathrm{SE}$ and performance, the importance of $\mathrm{SE}$ in organizational settings cannot be overlooked.

\section{References}

Appelbaum, SH. \& Hare, A., 1996, 'Self-Efficacy as a Mediator of Goal Setting and Performance: Some Human Resource Applications', Journal of Management Psychology, vol. 11, no.3, pp. 33-47.

Bandura, A., 1977, 'Self-Efficacy: Toward a Unifying Theory of Behavioral Change', Psychological Review, vol. 84, no. 2, pp. 191-215.

Bandura, A., 1981, 'Cultivating Competence, Self-Efficacy, and Intrinsic Interest Through Proximal Self-Motivation', Journal of Personality and Social Psychology, vol. 41, no. 3, pp. 586-598.

Bandura, A., 1993, 'Perceived SelfEfficacy in Cognitive Development and Functioning, Educational Psychologist, vol. 28, no. 2, pp. 117-148.

Compeau, DR., \& Higgins, CA., 1995, 'Computer Self-Efficacy: Development of a Measure and Initial Test', MIS Quarterly, vol. 19, no. 2, pp. 189-211.
Drucker, PF., 1999, 'KnowledgeWorker Productivity: The Biggest Challenge', California Management Review, vol. 12, no. 3, pp. 124-148.

Edision, EL., 1992, 'Career Assistant Principals: Job Satisfaction, SelfEfficacy, and Perceptions of Task Structure', PhD thesis, The Wayne State University, Detroit, MI.

Gist, ME., 1987, 'Self-Efficacy: Implications for Organizational Behavior and Human Resource Management', The Academy of Management Review, vol. 12, no. 3, pp. 472-485.

Hysong, SJ., \& Quinones, MA., 1997, 'The Relationship between SelfEfficacy and Performance: A MetaAnalysis', paper presented at the 12th Annual Conference of the Society for Industrial \& Organizational Psychology, St. Louis, MO.

Jones, GR., 1986, 'Socialization Tactics, Self-Efficacy, and Newcomer's Adjustments to Organizations', Academy of Management Journal, vol. 29 , no. 3, pp. 262-304.

Judge, TA., Shaw, JC., Jackson, CL \& Scott, BA., \& Rich, BL., 2007, 'SelfEfficacy and Work-Related Performance: The Integral Role of Individual Differences', Journal of Applied Psychology, vol. 92, no. 1, pp. 107-127. 
Kotler, P., 1999, Marketing Management, 10thedn, Prentice Hall, New York.

Locke, EA, Fredrick, E, Lee, C\&Bobko, P1984, 'The Effect of Self-Efficacy, Goals and Task Strategies on Task Performance', Journal of Applied Psychology, vol. 69, no. 2, pp. 241-251.

Neck, CP, Neck, HM, Manz, CC \& Godwin, J 1999, 'I Think I Can: I Think I Can; A Self leadership Perspective toward enhancing Entrepreneur thought Patterns, Self-Efficacy, and Performance', Journal of Management Psychology, vol. 14, no.6, pp. 477-501.

Orpen, C 1999, 'The Impact of SelfEfficacy on the Effectiveness of Employee Training', Journal of Workplace Learning, vol. 11, no. 4, pp. 119-122.

Robert, FM 1992, 'No Self-Efficacy No Performance',Training, vol. 12, no. 2, pp. 34-36.

Saks, A1995, 'A Longitudinal Field Investigation of the Moderating and Mediating Effects of Self-Efficacy on the Relationship between Training and Newcomer Adjustment',Journal of Applied Psychology, vol. 80, no. 3, pp. 211-225.

Schwoerer, CE\&May, DR2006, 'Age and Work Outcomes: The Moderating Effects of Self-Efficacy and Tool
Design Effectiveness', Journal of Organizational Behavior, vol. 17, no. 2, pp. 469-487.

Stajkovic, AD \& Luthans, F 1998, 'Self-Efficacy and Work-Related Performance: A Meta-Analysis', Psychological Bulletin, vol. 124, no. 2, pp. 240-261.

Tams, S 2008, 'Constructing SelfEfficacy at Work: A Person-centered Perspective', Personnel Review, vol. 37, no. 2 , pp. 165-183.

Tierney, P \& Farmer, SM 2002, 'Creative Self-Efficacy: Its Potential Antecedents and Relationship to Creative Performance', The Academy of Management Journal, vol. 45, no. 6, pp. 1137-1148.

Van, MV, Jong, MDT, Seydel, ER 2008, 'Contributions of Self-and Organizational Efficacy expectations to Commitment', Employee Relations, vol. 30, no. 2, pp. 142-155.

Zimmerman, BJ 2000, 'Self-Efficacy: An Essential Motive to Learn', Contemporary Educational Psychology vol. 25, pp. 82-91., 


\section{Appendix}

Table 1The Resulf Multivariate Test

\begin{tabular}{|c|c|c|c|c|c|c|}
\hline \multicolumn{7}{|c|}{$\begin{array}{c}\text { Tests of Within-Subjects Effects } \\
\text { Measure:MEASURE_1 }\end{array}$} \\
\hline \multicolumn{2}{|l|}{ Source } & $\begin{array}{l}\text { Type III } \\
\text { Sum of } \\
\text { Squares } \\
\end{array}$ & Df & $\begin{array}{l}\text { Mean } \\
\text { Square }\end{array}$ & $\mathbf{F}$ & Sig. \\
\hline \multirow[t]{4}{*}{ Training } & $\begin{array}{l}\text { Sphericity } \\
\text { Assumed }\end{array}$ & 70.939 & 1 & 70.939 & 265.231 & .000 \\
\hline & $\begin{array}{l}\text { Greenhouse- } \\
\text { Geisser }\end{array}$ & 70.939 & 1.000 & 70.939 & 265.231 & .000 \\
\hline & Huynh-Feldt & 70.939 & 1.000 & 70.939 & 265.231 & .000 \\
\hline & Lower-bound & 70.939 & 1.000 & 70.939 & 265.231 & .000 \\
\hline \multirow[t]{4}{*}{$\begin{array}{l}\text { SE * Type of } \\
\text { Training }\end{array}$} & $\begin{array}{l}\text { Sphericity } \\
\text { Assumed }\end{array}$ & 18.711 & 2 & 9.356 & 34.979 & .000 \\
\hline & $\begin{array}{l}\text { Greenhouse- } \\
\text { Geisser }\end{array}$ & 18.711 & 2.000 & 9.356 & 34.979 & .000 \\
\hline & Huynh-Feldt & 18.711 & 2.000 & 9.356 & 34.979 & .000 \\
\hline & Lower-bound & 18.711 & 2.000 & 9.356 & 34.979 & .000 \\
\hline \multirow[t]{4}{*}{$\begin{array}{l}\text { SE * Type of } \\
\text { Task }\end{array}$} & $\begin{array}{l}\text { Sphericity } \\
\text { Assumed }\end{array}$ & & 1 & & & \\
\hline & $\begin{array}{l}\text { Greenhouse- } \\
\text { Geisser }\end{array}$ & 6.806 & 1.000 & 6.806 & 25.445 & .000 \\
\hline & Huynh-Feldt & 6.806 & 1.000 & 6.806 & 25.445 & .000 \\
\hline & Lower-bound & 6.806 & 1.000 & 6.806 & 25.445 & .000 \\
\hline \multirow{4}{*}{$\begin{array}{l}\text { SE * Type of } \\
\text { Training * } \\
\text { Type of Task }\end{array}$} & $\begin{array}{l}\text { Sphericity } \\
\text { Assumed }\end{array}$ & 12.578 & 2 & 6.289 & 23.513 & .000 \\
\hline & $\begin{array}{l}\text { Greenhouse- } \\
\text { Geisser }\end{array}$ & 12.578 & 2.000 & 6.289 & 23.513 & .000 \\
\hline & Huynh-Feldt & 12.578 & 2.000 & 6.289 & 23.513 & .000 \\
\hline & Lower-bound & 12.578 & 2.000 & 6.289 & 23.513 & .000 \\
\hline \multirow[t]{4}{*}{ Error(SE) } & $\begin{array}{l}\text { Sphericity } \\
\text { Assumed }\end{array}$ & 22.467 & 84 & & & \\
\hline & $\begin{array}{l}\text { Greenhouse- } \\
\text { Geisser }\end{array}$ & 22.467 & 84.000 & .267 & & \\
\hline & Huynh-Feldt & 22.467 & 84.000 & .267 & & \\
\hline & Lower-bound & 22.467 & 84.000 & .267 & & \\
\hline
\end{tabular}

